\title{
Effects of inhaled tumour necrosis factor alpha in subjects with mild asthma
}

\author{
P S Thomas, G Heywood
}

Thorax 2002;57:774-778

See end of article for authors' affiliations

......................

Correspondence to:

Dr P S Thomas, Department

of Respiratory Medicine,

Prince of W ales Hospital,

Randwick, N SW 2031

Australia;

paul.thomas@unsw.edu.au

Revised version received

$18 \mathrm{M}$ arch 2002

Accepted for publication

19 March 2002

shown to induce air-

Background: Inhaled tumour necrosis factor alpha (TN F $\alpha$ ) has previously been shown to induce air-
way neutrophilia and increased airway reactivity in normal subjects. It was hypothesised that a similar challenge would increase airway reactivity in those with mild asthma, but that the inflammatory profile may differ.

Methods: Ten mild asthmatic subjects were recruited on the basis of clinical asthma and either a sensitivity to methacholine within the range defined for asthma or a $20 \%$ improvement in forced expiratory volume $\left(\mathrm{FEV}_{1}\right)$ after $200 \mu \mathrm{g}$ salbutamol. Subjects inhaled either vehicle control or $60 \mathrm{ng}$ recombinant human (rh)TN F $\alpha$ and were studied at baseline, 6, 24, and 48 hours later. Variables included spirometric parameters, methacholine provocative concentration causing a $20 \%$ fall in $\mathrm{FEV}_{1}\left(\mathrm{PC}_{20}\right)$, induced sputum differential cell count, relative sputum level of mRN A of interleukins (IL)-4, IL-5, IL-9, IL-14, IL-15 and TN $F \alpha$, and the exhaled gaseous markers of inflammation, nitric oxide and carbon monoxide.

Results: $P_{20}$ showed an increase in sensitivity after TN F $\alpha$ compared with control $(p<0.01)$. The mean percentage of neutrophils increased at 24-48 hours (24 hour control: 1.1 (95\% Cl 0.4 to 2.7 ) v 9.2 $(95 \% \mathrm{Cl} 3.5$ to 14.9$), p<0.05)$, and there was also a rise in eosinophils $(p=0.05)$. Relative levels of sputum mRN A suggested a rise in expression of TN F $\alpha$, IL-14, and IL-15, but no change in IL-4 and IL-5. Spirometric parameters and exhaled gases showed no significant change.

Conclusion: The increase in airway responsiveness and sputum inflammatory cell influx in response to rhTN F $\alpha$ indicates that TN F $\alpha$ may contribute to the airway inflammation that characterises asthma.

$\mathrm{M}$ any mediators have been implicated in the pathogenesis of allergic asthma. The initial events in previously sensitised allergic asthmatic subjects involve specific IgE cross linking after allergen inhalation, followed by the degranulation and activation of the IgE sensitised mast cell. This cell releases well characterised preformed mediators including histamine and proteases such as chymase and tryptase, as well as eicosanoids. M ore recently it has become clear that the mast cell stores cytokines in cytoplasmic granules. These cytokines include TNF alpha $(T N F \alpha)$ which can be upregulated by recognised growth factors for the mast cell such as stem cell factor (SCF, or c-kit ligand). ${ }^{12}$

It is becoming increasingly apparent that TNF $\alpha$ plays a role in asthma. TNF $\alpha$ mRNA is more frequently expressed in the airway of asthmatic subjects than normal subjects and increased release of this cytokine has been shown from the bronchoalveolar lavage (BAL) cells of asthmatic subjects. ${ }^{3}$ Also, lipopolysaccharide inhalation by mild asthmatic subjects induces TNF $\alpha$ secretion into BAL fluid and is associated with increased airway reactivity. ${ }^{45}$ In addition, after allergen challenge TNF $\alpha$ is found to be increased in the BAL fluid of asthmatic subjects, and their peripheral blood monocytes generate more of this cytokine ${ }^{67}$ Previous work has shown that TNF $\alpha$ causes hyperresponsiveness in rats, ${ }^{8}$ and in man it has been found that exogenous TNF $\alpha$ can induce a neutrophil influx followed by increased airway reactivity in normal subjects. ${ }^{9}$ It was hypothesised that a similar inhalational challenge may induce an increase in airway reactivity in patients with mild asthma, and that the inflammatory influx may differ from the previous study group of normal subjects.

\section{METHODS}

The protocol was approved by the committee on ethical procedures in human subjects of the University of New South Wales. Informed consent was obtained from all participants in the trial.
Subjects and reagents

Ten mild asthmatic subjects (three women) were recruited to the study on the basis of clinical asthma without use of inhal ed glucocorticosteroids in the last 3 months, and either a sensitivity to methacholine within the range defined for asthma or a $20 \%$ improvement in forced expiratory volume in the first second $\left(\mathrm{FEV}_{1}\right)$ after salbutamol. None were current smokers or had a $>1$ pack year history of smoking. Subjects were assessed for atopy by symptom questionnaire and skin prick testing with common allergens including Felix domesticus, Dermatophagoides pteronyssinus, Aspergillus fumigatus, and mixed grasses (Bayer, Pymble, Sydney, Australia). Atopy was defined as seasonal conjunctivitis/hayfever and by a skin prick test $>2 \mathrm{~mm}$ larger than the negative control. Table 1 shows the characteristics of the study subjects.

Reagents were purchased from Sigma Australia unless otherwise specified.

\section{Study design and protocol}

The design was that of a double blind, placebo controlled, randomised, crossover study using within subject comparison. On the first study day subjects underwent spirometric testing followed by methacholine challenge and sputum induction, and then inhaled either nebulised recombinant human (rh) TNF $\alpha$ (60 ng, Bioscientific, Gymea, Australia) in 1\% human albumin-phosphate buffered saline ${ }^{9}$ or vehicle control. Subjects were monitored for 6 hours and then a further sputum induction was performed. Methacholine challenge and sputum induction were repeated at 24 and 48 hours after test inhalation. After an interval of 6 weeks the alternate arm of the study was performed with the same variables being assessed. Variables studied were: spirometric parameters, methacholine responsiveness, cellular profile and cytokine mRNA of induced sputum, exhaled nitric oxide (eNO) and carbon monoxide (eCO). 


\begin{tabular}{|c|c|c|c|c|}
\hline Subject & Age/sex & $\mathrm{FEV}_{1}(\%$ predicted $)$ & $\begin{array}{l}\text { Methacholine } \mathrm{PC}_{20} \\
(\mathrm{mg} / \mathrm{ml})\end{array}$ & Atopy \\
\hline 1 & $41 / M$ & 73.5 & 4.24 & Yes \\
\hline 2 & $35 / M$ & 107.1 & 3.22 & Yes \\
\hline 3 & $27 / F$ & 103.1 & 4.70 & Yes \\
\hline 4 & $26 / F$ & 71.0 & 0.23 & Yes \\
\hline $5 *$ & $25 / F$ & 95.8 & $>16$ & No \\
\hline 6* & $29 / M$ & 99.5 & $>16$ & No \\
\hline 7 & $38 / M$ & 85.7 & 2.11 & Yes \\
\hline 8 & $33 / \mathrm{M}$ & 91.7 & 0.93 & Yes \\
\hline 9 & $42 / M$ & 103.0 & 3.12 & Yes \\
\hline 10 & $28 / M$ & 81.5 & 2.46 & Yes \\
\hline
\end{tabular}

Spirometry and bronchial responsiveness

At the same time of day, subjects initially performed baseline spirometric tests according to ATS recommendations using a dry wedge spirometer (Vitalograph; Buckingham, UK) to derive $\mathrm{FEV}_{1}$ and forced vital capacity $(\mathrm{FVC}) .{ }^{10} \mathrm{~A}$ standard methacholine ( $\mathrm{MCh}$ ) challenge test ${ }^{11}$ was then administered. Briefly, subjects inhaled $0.9 \%$ saline five times by slow inspiration from functional residual capacity to total lung capacity over 1 second using a $M$ efar dosimeter ( $M$ efar, Brescia, Italy) and then held their breath for 6 seconds. FEV 1 was measured 2 minutes later. Doubling concentrations of methacholine from 0.0625 to $128 \mathrm{mg} / \mathrm{ml}$ were inhaled until either a $20 \%$ fall in $\mathrm{FEV}_{1}$ occurred or the concentration of $128 \mathrm{mg} / \mathrm{ml}$ was reached. Results are expressed as the logarithm of the dose needed to cause a $20 \%$ fall in $\mathrm{FEV}_{1}\left(\log \mathrm{PC}_{20}\right)$. Airway obstruction was reversed by $200 \mu \mathrm{g}$ inhaled salbutamol .

\section{Sputum induction}

Sputum induction was performed using a method previously described. ${ }^{9}$ Briefly, subjects inhaled nebulised $3.5 \%$ saline and lavaged orally with water before voluntary coughing every 2.5 minutes until $5 \mathrm{ml}$ sputum was obtained or 20 minutes had elapsed. Sputum was solubilised by incubation with $1 \mathrm{mmol}$ dithiothreitol in phosphate buffered saline (PBS) made up to a total volume of $10 \mathrm{ml}$ and incubated for 15 minutes at $37^{\circ} \mathrm{C}$. Cells were then washed thrice in PBS, the cell pellet resuspended, and the total number of pulmonary cells was counted by toluidine blue staining using a haemocytometer. A sample of cells from each preparation was mounted on slides, fixed with methanol, and sequentially stained with eosin and methylene blue dyes. A differential cell count was performed by applying standard morphometric criteria to the first 400 identifiable pulmonary cells. Sputum preparation for cytokine analysis was performed as previously described. ${ }^{12}$ Briefly, sputum was stored in denaturing solution ${ }^{13}$ consisting of guanadinium, sarcosyl, and $\beta$-mercaptoethanol.

\section{Cytokine mRNA analysis}

Total RNA was extracted using the acid-guanadinium thiocyanoate-phenol-chloroform method. ${ }^{13}$ RNA was precipitated with isopropanol in the presence of glycogen, resuspended in denaturing solution, re-precipitated, and washed in ethanol. Adjustments were made to ensure that RNA from an equivalent number of pulmonary cells was used.

RNase protection assays were performed on sputum specimens according to the manufacturer's instructions (RiboQuant, Pharmingen, San Diego, CA, USA), and mRNA expression determined for TNF $\alpha$, IL-2, IL-4, IL-5, IL-9, IL-13, IL-14, IL-15, and interferon (IFN) $\gamma$. Briefly, sample RNA was hybridised to the $\left\{\alpha^{32} \mathrm{P}\right\}$ dUTP-labelled hCK-1 probe set and the single stranded RNA digested with a RNase A/T1 mixture before purification and electrophoretically size separated on a $5 \%$ polyacrylamide gel (PAGE). The dried gel was subjected to densitometry and phosphorimager analysis to evaluate the protected bands. Data were expressed as the ratio derived from cytokine/GAPDH density in each lane for each individual. Positive controls consisted of human RNA for each cytokine and yeast tRNA was a negative control; RNA quality was assessed by PAGE.

Exhaled nitric oxide

Exhaled nitric oxide (eNO) was measured online using a chemiluminescence analyser (Dasibi, Glendale, CA, USA) adapted for online measurement by the method of K haritonov et $\mathrm{al}_{1}{ }_{14}^{14}$ which has been verified as uncontaminated by nasal $\mathrm{NO}^{15}$ and complies with current standards published by the ATS and ERS. ${ }^{16}{ }^{17}$ Subjects exhaled using a slow vital capacity manoeuvre maintaining a positive oral pressure to exclude nasal contamination, and the mean of three peak plateau readings was taken.

Exhaled carbon monoxide levels (eCO) were also measured simultaneously (Leybold-Heraeus Binos 1, Hanau, Germany) via a side arm and the peak plateau levels were recorded. NO free gas and standard concentrations of $\mathrm{NO}$ and $\mathrm{CO}$ gases (BOC, Sydney) were used to calibrate the analysers.

\section{Statistical analysis}

Previous work using the primary end point of change in methacholine $\log \mathrm{PC}_{20}$ sensitivity and a standard deviation of 0.22 suggested that a significant change would be detected with eight subjects $(\alpha=0.05,1-\beta=0.8) .{ }^{9}$ Data are expressed as mean ( $95 \%$ confidence interval, $\mathrm{Cl}$ ) unless otherwise indicated, while log data are expressed as geometric means. Statistical analysis was performed by repeated measures analysis of variance (ANOVA) for data conforming to the Normal distribution with significant results being further analysed by post hoc Bonferroni corrected t tests for multiple comparisons. The Wilcoxon sign rank test was applied to data with a non-parametric distribution. ${ }^{18}$

\section{RESULTS}

Subjects

All of the subjects tolerated the procedures without incident, but unfortunately one subject failed to complete one arm of the study despite repeated invitations to return. The data are analysed using the remaining nine subjects.

\section{Spirometry}

There was a small fall in mean $\mathrm{FEV}_{1}$ from 3.55 I $(95 \% \mathrm{Cl} 1.82$ to 5.28$)$ to $3.50 \mathrm{I}(95 \% \mathrm{Cl} 1.7$ to 5.33$) 24$ hours after rhTNF $\alpha$ (control: from 3.59 I ( $95 \% \mathrm{Cl} 1.63$ to 5.5 ) to 3.56 I ( $95 \% \mathrm{Cl} 1.8$ to 5.2)). This did not reach statistical significance. FVC did not show any significant change at any of the time points.

\section{Methacholine responsiveness}

Comparing the TNF $\alpha$ inhalation phase with the sal ine vehicle phase, there was a significant difference between the two groups. The same subjects showed an increase in sensitivity to 


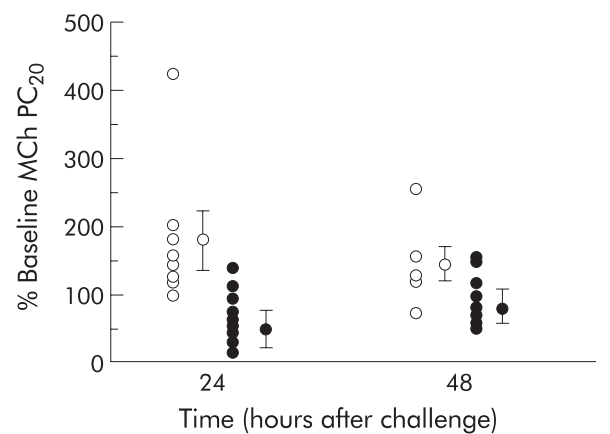

Figure 1 Effect of control or tumour necrosis factor alpha (TN F $\alpha$ ) inhalation upon $\log \mathrm{PC}_{20}$ expressed as percentage of the baseline value after 24 and 48 hours. 0 pen symbols=control challenge; closed symbols $=60 \mathrm{ng}$ rhTN $F \alpha$ challenge. M ean and SE values are also shown (AN O VA, $p<0.01$; post hoc Bonferroni corrected $t$ test, $p<0.05$ at 24 hours).

methacholine after inhaling $\operatorname{rhTNF} \alpha$, and the difference between the two treatments reached statistical significance at 24 hours, as shown in fig 1 (mean difference $83.2 \%, 95 \% \mathrm{Cl}$ 33.3 to 133.1, Bonferroni corrected post hoc t test, $p<0.05$ ). Repeated methacholine challenge led to a decrease in sensitivity during the control arm, as previously observed. ${ }^{911}$ All subjects achieved a $\mathrm{MCh} \mathrm{PC}_{20}$, including the two subjects with a baseline value of $>16 \mathrm{mg} / \mathrm{ml}$ who required an upper doubling dilution of $128 \mathrm{mg} / \mathrm{ml}$.

Sputum inflammatory differential cell counts After TNF $\alpha$ inhalation there was a significant increase in the percentage of sputum neutrophils at 24 hours (mean difference $8.1 \%, 95 \% \mathrm{Cl} 6.3$ to 9.9 , post hoc Bonferroni corrected t test, $\mathrm{p}<0.05$ ) and at 48 hours (mean difference $3.4 \%, 95 \% \mathrm{Cl} 1.8$ to 5.0 , Bonferroni corrected t test, $\mathrm{p}<0.02$ ) and an increase also in eosinophils at 24 hours (mean difference $1.5 \%, 95 \% \mathrm{Cl} 1.3$ to 1.7 , Bonferroni corrected t test, $\mathrm{p}=0.05$ ) compared with the control arm of the study (fig 2). The maximum increase in both of these inflammatory cells was seen at 24 hours and was beginning to subside by 48 hours. There was a non-significant rise in the percentage of lymphocytes over the same time period. No significant changes were seen in the percentage of columnar cells or total number of macrophages.

Cytokine analysis

Messenger RNA from the sputum at 0, 6, 24 and 48 hours after rhTNF $\alpha$ inhalation showed an increase in IL-14, IL-15, and TNF $\alpha$ message compared with the control arm in the majority of subjects at 6 hours only and, although this did not achieve statistical significance (Wilcoxon sign rank test, data not shown), it would be the expected time at which other mediators would be induced. The remaining cytokines showed no increase in message above baseline.

\section{Exhaled $\mathrm{NO}$ and $\mathrm{CO}$}

There was a non-significant rise in both eNO and eCO after both control and rhTNF $\alpha$ inhalation. Exhaled NO 24 hours after TNF inhalation, expressed as percentage of baseline, was $110.0 \%$ (95\% Cl 80.0 to 139.9 ) compared with $109.8 \%(95 \% \mathrm{Cl}$ 97.8 to 121.8) in controls; after 48 hours the corresponding values were $99.7 \%(95 \% \mathrm{Cl} 52.6$ to 146.7$)$ and $101.3 \%(95 \% \mathrm{Cl}$ 54.8 to 147.8$)$, respectively.

Exhaled CO 24 hours after TNF $\alpha$ inhalation, expressed as percentage baseline, was $108.3 \%$ (95\% Cl 89.9-126.7) compared with $122.6 \%$ ( $95 \% \mathrm{Cl} 96.3$ to 148.9 ) in controls; after 48 hours the corresponding values were $82.1 \%(95 \% \mathrm{Cl} 54.5$ to $109.7)$ and $109.7 \%(95 \% \mathrm{Cl} 94.2$ to 125.2$)$, respectively.
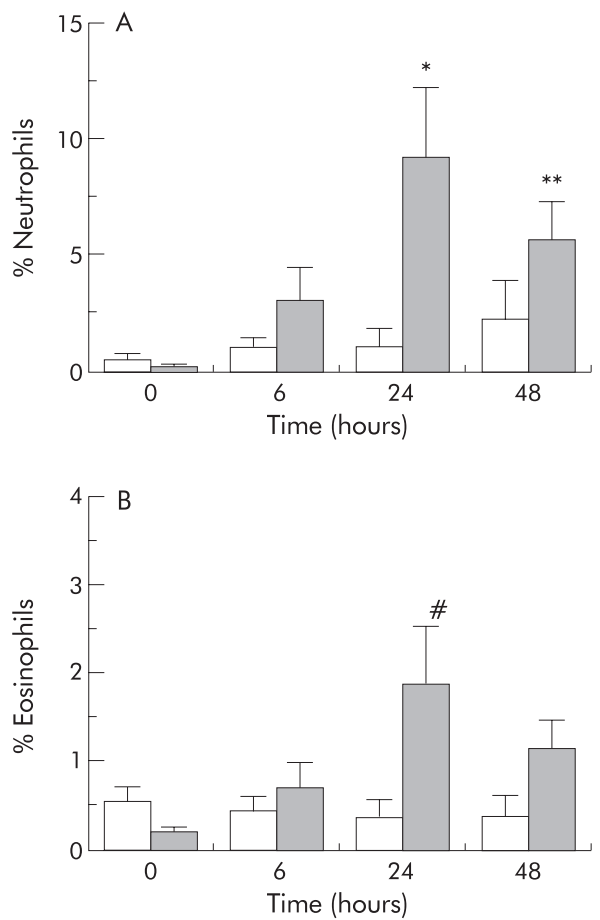

Figure 2 (A) Effect of control (open bars) or tumour necrosis factor alpha (TN F $\alpha$, shaded bars) inhalation on change in percentage neutrophils from baseline for the 3 days of the study (AN OVA, $p<0.01$; post hoc Bonferroni corrected t test, $* p<0.05, * * p<0.02)$. (B) Effect of control or tumour necrosis factor alpha (TN F $\alpha$ ) inhalation on change in percentage eosinophils from baseline for the 3 days of the study (AN O VA, $p<0.05$; post hoc Bonferroni corrected $t$ test, $\# p=0.05$ ).

\section{DISCUSSION}

TNF $\alpha$ is a multifunctional cytokine with a wide range of activities. It has been implicated in a number of diseases including asthma, ${ }^{5}$ rheumatoid arthritis, multiple sclerosis, and other inflammatory disorders. It is implicated in cell death and apoptosis but it is able also to generate a non-cytotoxic inflammatory response in certain situations. It has been shown conclusively to be rel eased immediately from mast cells after encounter with specific allergens, ${ }^{2}{ }^{1920}$ and is therefore implicated in allergic asthma.

TNF $\alpha$ is associated with the local upregulation of the adhesion molecules E-selectin, VCAM-1, and ICAM-1 which are involved in leucocyte migration. Both VCAM-1 and ICAM-1 have been shown to be involved in the transmigration of granulocytes across endothelial cultures in vitro ${ }^{21-23}$ and increased VCAM - 1 expression is associated with a preponderance of TNF $\alpha$ in eosinophilic nasal polyposis. ${ }^{24}$ TNF $\alpha$ appears to exert its effect on the increased migration of eosinophils and neutrophils through these adhesion factors, with increased eosinophil attachment reliant upon $\alpha_{4}$ integrin binding to the upregulated VCAM-1 expression ${ }^{23}$ and migration associated with upregulated ICAM-1 expression,, ${ }^{22}$ although neutralising experiments have implicated the $\beta_{2}$ integrins. ${ }^{25}$ TNF $\alpha$ supports GM-CSF mediated eosinophil migration, which is dose dependent for both cytokines, and this migration is inhibited by actinomycin D. Both TNF $\alpha$ and IL-1 $\beta$ increase ICAM - 1 expression and antibodies to ICAM - 1 inhibit this migration through human umbilical vein endothelial cells (HUVEC), and may therefore act in concert with IL-5 in this regard. ${ }^{22}$ In asthma, TNF $\alpha$ is more frequently expressed in the airways than in normal subjects, and in allergic polyposis this increase in TNF $\alpha$ is associated with an increase in VCAM-1 and eosinophilic infiltration. ${ }^{24}{ }^{26}$ It has become apparent that, although eosinophil migration is classically 
thought to depend upon eotaxin, IL-4, IL-5, and GM-CSF, there is evidence now to suggest that TNF $\alpha$ can upregulate cells to express I L- $5^{27}$ and eotaxin. ${ }^{28}$

The migration of neutrophils into the airway as demonstrated by these experiments in asthmatic subjects confirms our previous findings in normal non-asthmatic subjects. ${ }^{9}$ This sputum neutrophilia is associated with an increase in airway reactivity and these findings would fit the hypothesis that airway inflammation induces increased airway reactivity. Sputum neutrophilia is seen in asthma, particularly fatal asthma, ${ }^{29-31}$ although it is recognised less often than the association of asthma with sputum eosinophilia. Sputum neutrophilia could be the result of TNF $\alpha$ rel ease from allergen activated mast cells and macrophages, or via bacterial activation. It is now apparent that both neutrophils and eosinophils are associated with the late phase of the allergic response. ${ }^{32-34}$ Neutrophils are associated in asthma with increased migratory responses, superoxide generation, and increased bronchial ring contractility. ${ }^{35-37}$

Induced sputum mRNA suggested an increase in message for TNF $\alpha, I L-14$, and IL-15. The roles of IL-14 and IL-15 have not yet been clarified in asthma, but it is becoming apparent that IL-15 has potent growth factor activity for mast cells in vitro $^{38}$ and thus may be a mechanism for perpetuating the allergic inflammatory response. The finding that sputum TNF $\alpha$ mRNA was increased after TNF $\alpha$ exposure was unexpected as a negative feedback mechanism might have been anticipated. It is possible that, on exposure to a low dose of rhTNF $\alpha$, there is an initial amplification of activation before inhibitory mechanisms come into play. It was likewise anticipated that IL-5 would be upregulated by the nebulised TNF $\alpha$ as it has been shown to upregulate IL-5 and downregulate IL-4. ${ }^{39}$ Neither change was seen but, again, it is difficult to know whether the local dose delivered in this study would have been comparable to other reports. The dose of rhTNF $\alpha$ used was, however, comparable to previous reports of total TNF isolated from BAL fluid after allergen challenge. ${ }^{7}$

Exhaled gas analysis failed to show any significant changes. This may have been because of the small number of study subjects, and there are no data in the literature to suggest an appropriate sample size but, importantly, it also could be masked by saline challenge for sputum induction. Sputum induction by itself will generate a neutrophil sputum leucocytosis at about 24 hours $^{9}$ and this may be the mechanism whereby a slight increase in eNO and eCO is seen in this arm of the study. To show a separate effect of inhaled rhTNF $\alpha$ al one would require a different study design without the induction of sputum. TNF $\alpha$ has been described as upregulating inducible NO synthase ${ }^{40}{ }^{41}$ and it would be expected that this might be reflected in an increase in eNO, but possibly a larger dose of nebulised TNF $\alpha$ would be required to demonstrate this effect.

In conclusion, it appears that small quantities of cytokines such as TNF $\alpha$ can have proinflammatory effects that are measurable in the airways of subjects with mild asthma. While glucocorticosteroids are the most effective means of inhibiting this inflammation, it is possible that, by inhibiting these cytokines directly, a reduction in airway inflammation and reactivity may be achieved and could be a useful method of reducing exposure to glucocorticosteroids.

\section{ACKNOWLEDGEMENTS}

This study was funded by the NH\&M RC, Australia. The authors thank the subjects for donating their time.

\section{Authors' affiliations}

P S Thomas, G Heywood, Inflammation Research Unit, School of Pathology, Faculty of M edicine, University of N ew South W ales, Sydney, Australia and Department of Respiratory M edicine, Prince of $\mathrm{W}$ ales Hospital, Randwick, N SW 2031

\section{REFERENCES}

1 Thomas PS, Pennington DW, Gold W M, et al. M ast cells contain authentic $17 \mathrm{kD}$ tumor necrosis factor $\alpha$. Am Rev Respir Dis 1991;143:A394.

2 Thomas P, Pennington D, Schreck R, et al. A uthentic $17 \mathrm{kD}$ tumor necrosis factor $\alpha$ is synthesized and released from canine mast cells and up-regulated by stem cell factor. Clin Exp Allergy 1996;26:710-8

3 Cembrzynska-Nowak M, Szklarz E, Inglot A, et al. Elevated release of tumor necrosis factor-alpha and interferon-gamma by bronchoalveolar leukocytes from patients with bronchial asthma. Am Rev Respir Dis 1993;147:291-5

4 Michel O, G inanni R, LeBon B, et al. Inflammatory response to acute inhalation of endotoxin in asthmatic patients. Am Rev Respir Dis $1992 ; 146: 352-7$

5 Thomas PS. Tumour necrosis factor alpha: the role of this multifunctional cytokine in asthma. Immunol Cell Biol 2001;79:132-40.

6 Gosset $P$, Tsicopoulos A, W allaert B, et al. Increased secretion of tumor necrosis factor alpha and interleukin-6 by alveolar macrophages consecutive to the development of the late asthmatic reaction. J Allergy Clin Immunol 1991;88:561-71.

7 Gosset $\mathrm{P}$, Tsicopoulos A, W alla ert B, et al. Tumor necrosis factor alpha and interleukin-6 production by human mononuclear phagocytes from allergic asthmatics after IgE-dependent stimulation. Am Rev Respir Dis $1992 ; 146: 768-74$

8 Kips JC, Tavernier J, Pauw els RA. Tumor necrosis factor causes bronchial hyper-responsiveness in rats. Am Rev Respir Dis 1992;145:332-6.

9 Thomas PS, Yates DH, Barnes PJ. Tumor necrosis factor alpha increases airway responsiveness and sputum neutrophilia in normal human subjects. Am J Respir C rit Care M ed 1995;152:76-80.

10 American Thoracic Society. Standardization of spirometry, 1994 update. Am J Respir Crit Care Med 1995;152:1107-36.

11 Hargreave F, Ryan G, Thomson N, et al. Bronchial responsiveness to hista mine or methacholine in asthma: measurement and clinical significance. J Allergy Clin Immunol 1981;68:1126-31.

12 Gelder C, Thomas P, Yates D, et al. Cytokine expression in normal, atopic and asthmatic subjects using the combination of sputum induction and the polymerase chain reaction. Thorax 1995;50:1033-7.

13 Chomczynski P, Sacchi N. Single-step method of RN A isolation by acid guanidinium thiocyanate-phenol-chloroform extraction. A nal Biochem $1987 ; 162: 156-9$

14 Kharitonov S, Yates D, Robbins R, et al. Endogenous nitric oxide is increased in the exhaled air of asthmatic patients. Lancet 1994;343:133-5.

15 Kharitonov S, Barnes P. N asal contribution to exhaled nitric oxide during exhalation against resistance or during breath holding. Thorax $1997 ; 52: 540-4$

16 Kharitonov S, Alving K, Barnes P. Exhaled and nasal nitric oxide measurements: The European Respiratory Society Task Force recommendations. Eur Respir / 1997:10:1683-93.

17 American Thoracic Society. Recommendations for standardized procedures for the online and offline measurement of exhaled lower respiratory nitric oxide and nasal nitric oxide in adults and children: 1999. Am Respir Crit Care Med 1999;160:2104-17.

18 Altman DG. Practical statistics for medical research. London: Chapman \& Hall, 1991.

19 Gordon J F, G alli SJ. M ast cells as a source of both preformed and inducible TN F- $\alpha$ / cachectin. N ature 1990;346:274-6.

20 Walsh L, Trinchieri G, W aldorf $\mathrm{H}$, et al. Human dermal mast cells contain and release tumor necrosis factor alpha which induces endothelial adhesion molecule 1. Proc $N$ att Acad Sci 1991;88:4220-4.

21 Bittleman D, Erger R, Cassale T. Cytokines induce selective granulocyte chemotactic responses. Inflammation Res 1996;45:89-95.

22 Erger R, Casale T. Tumor necrosis factor alpha is necessary for granulocyte-macrophage colony stimulating factor-induced eosinophil transend othelial migration. Int A rch Allergy Immunol 1998;115:24-32.

23 Yamamoto $\mathrm{H}$, Sedgwick JB, Busse W W. Differential regulation of eosinophil adhesion and transmigration by pulmonary microvascular endothelial cells. J Immunol 1998;161:971-7.

24 Hamilos $D$, Leung $D, W$ ood $R$, et al. Eosinophil infiltration in nonallergic chronic hyperplastic sinusitis with nasal polyposis (CHS/N P) is associated with endothelial VCAM-1 expression and expression of TN alpha. Am J Respir Cell M ol Biol 1996;15:443-50.

25 Godding V, Stark J, Sedgwick J, et al. Adhesion of activated eosinophils is enhanced by tumor necrosis factor alpha and interleukin-1 beta. Am J Respir Crit Care Med 1995;13:555-62

26 Ying S, Robinson DS, Varney V, et al. TN F-alpha mRN A expression in allergic inflammation. Clin Exp Allergy 1991;21:745-50.

27 Zhang K, G haraee-Kermani M, M CG arry B, et al. TN F-alpha mediated lung cytokine networking and eosinophil recruitment in pulmonary fibrosis. Immunology 1997;158:954-9.

28 Ghaffar O, Hamid Q, Renzi PM, et al. Constitutive and cytokine-stimulated expression of eotaxin by human airway smooth muscle cells. Am J Respir Crit Care Med 1999;159:1933-42.

29 Boschetto P, Mapp C, Picotti G, et al. N eutrophils and asthma. Eur Respir J $1989 ; 2$ (Suppl):456-9s.

30 Fahy J, Kim K, Liu J, et al. Prominent neutrophilic inflammation in sputum from subjects with asthma exacerbation. J Allergy Clin Immunol 1995;95:843-53

31 Carroll N, Carello S, Cooke C, et al. Airway structure and inflammatory cells in fatal attacks of asthma. Eur Respir J 1996;9:709-15.

32 Metzger WJ, Richerson HB, W orden K, et al. Bronchoalveolar lavage of allergic asthmatic patients following allergen bronchoprovocation. Chest $1986 ; 89: 477-83$. 
33 Nagy L, Lee TH, Kay AB. N eutrophil chemotactic activity in antigen induced late asthmatic reactions. N Engl I Med 1982;306:497-501.

34 Diaz P, G onzales C, Galleuillos F, et al. Eosinophils and macrophages in bronchial mucus and bronchoalveolar lavage during allergen-induced late-phase asthmatic reactions. I Allergy Clin Immunol 1986;77:244-9.

35 Meltzer S, Goldberg B, Lad P, et al. Superoxide generation and its modulation by adenosine in the neutrophils of subjects with asthma.J Allergy Clin Immunol 1989;83:960-6.

36 Håkanssonn L, Carlson M, Stålenheim G, et al. M igratory responses of eosinophil and neutrophil granulocytes from patients with asthma. I Allergy Clin Immunol 1990:85:743-50.

37 Hallahan AR, Armour CL, Black JL. Products of neutrophils and eosinophils increase the responsiveness of human isolated bronchial tissue. Eur Respir J 1990;3:554-8.
38 Tagaya $Y$, Burton I, M iyamoto $Y$, et al. Identification of a novel receptor/ signal transduction pathway for IL-15/T in mast cells. EMBO J $1996 ; 15: 4928-39$.

39 Hart PH, Vitti G F, Burgess DR, et al. Potential anti-infla mmatory effects of interleukin-4: suppression of human monocyte tumor necrosis factor alpha, interleukin-1, and prostaglandin E2. Proc N atl Acad Sci USA $1989 ; 86: 3803-7$

40 Kwon S, George S. Synergistic cytokine-induced nitric oxide production in human alveolar epithelial cells. $N$ itric 0 xide 1999;3:348-57.

41 Robbins RA, Barnes PJ, Springall DR, et al. Expression of inducible nitric oxide in human lung epithelial cells. Biochem Biophys Res Comm $1994 ; 203: 209-18$

\section{Clinical Evidence-Call for contributors}

Clinical Evidence is a regularly updated evidence based journal available world wide both as a paper version and on the internet. Clinical Evidence urgently needs to recruit a number of new contributors. Contributors a re health care professionals or epidemiologists with experience in evidence based medicine and the ability to write in a concise and structured way.

We are presently interested in finding contributors with an interest in the following clinical areas:

Angina pectoris

Attention deficit hyperactivity disorder

Genital warts

Hepatitis B

\author{
Hepatitis C \\ HIV \\ Influenza \\ Varicose veins
}

Being a contributor involves:

- Appraising the results of literature searches (performed by our Information Specialists) to identify high quality evidence for inclusion in the journal.

- W riting to a highly structured template (about 1500-3000) words), using evidence from selected studies, within 6-8 weeks of receiving the literature search results.

- W orking with Clinical Evidence Editors to ensure that the text meets rigorous epidemiological and style standards.

- Updating the text every eight months to incorporate new evidence.

- Expanding the topic to include new questions once every eight months to incorporate new evidence.

- Expanding the topic to include new questions once every 12-18 months.

If you would like to become a contributor for Clinical Evidence or require more information about what this involves, please send your contact details and a copy of your $C V$, clearly stating the clinical area you are interested in, to Polly Brown (pbrown@bmjgroup.com). 